\title{
An audit on the outcome of vaginal Birth after Caesarean Section (VBAC) in a Sri Lankan tertiary care setting and factors associated with failure.
}

\author{
Tilakaratna $\mathrm{TJ}^{1}$, Palihawadana $\mathrm{TS}^{2}$, Fernandopulle $\mathrm{RC}^{3}$
}

\section{Abstract}

Introduction: Caesarean section is a major surgical operation and its rate is on the rise in Sri Lanka as well as in the world. It is recommended to lower the Caesarean section rate due to the risk of potential complications and burden on the health care system. Previous Caesarean is a common indication for planned Caesarean section and vaginal birth after Caesarean section (VBAC) is considered a safe alternative for many women. This audit study was aimed at determining the success rate of VBAC in a local setting and to identify the factors that are associated with failure in this study population.

Method: An audit study was carried out in two obstetric units if South Colombo Teaching hospital, Kalubowila and De Soysa hospital for women, Colombo 8 to assess the success rate among women who underwent VBAC. The unit policies included patient choice for decision to undergo VBAC and non-usage of medication either for induction or augmentation of labour. The audit standards were set as a VBAC success rate of 72\% (RCOG Green-top guidelines) and a low APGAR ( $<7$ ) in less than $2 \%$ of neonates (set by clinical experience). The demographic and past obstetric factors were compared between groups to determine significant associations.

Results: A total of 161 women (37.8\% of those with a previous one Caesarean) had opted to undergo VBAC during the study period. It was successful in $69.6 \%$ of the total study sample and $84.6 \%$ who has had a previous vaginal delivery. Low APGAR scores at 5 minutes was observed in two neonates (1.2\%) and both these were in the group with a successful VBAC.

The factors associated with failed VBAC in this study population included not having had a previous vaginal delivery (Odds ratio 2.99), poor progress of labour being the indication for previous section (OR 2.32), a cervical dilatation of $<2 \mathrm{~cm}$ at onset of labour (OR 4.43), malpositions in early labour (OR 12.24), and a birth weight of more than $3000 \mathrm{~g}$ (OR 2.11). Other preciously described factors such as a high BMI and inter-delivery interval failed to show a significant association in this study group.

Discussion and recommendations: The take up rate of VBAC in our study population seems to be low. However, the study did not study the reasons contributing to this low rate hence no recommendations can be made. The success rate of VBAC on our group (69\%) was very close to the set standards (72\%) and the rate of low APGAR at 5 minutes was $1.2 \%$ and was achieving the set standard. These figures along with the factors identified to be associated with the failure at VBAC should be used for patient counseling in our local setting. Other units also should carry out such audit projects to find out the success rate of VBAC in their respective units. More in-depth studies should be carried out to find causes for low rate of undergoing VBAC and to determine effective ways to improve it.

\footnotetext{
${ }^{1}$ Colombo South Teaching hospital, Kalubowila

${ }^{2}$ Department of Obstetrics \&Gynaecology, University of Kelaniya

${ }^{3}$ Department of Obstetrics \&Gynaecology, University of Sri Jayewardenepura

Correspondence: Tilakaratna TJ

E-mail: jayangat@gmail.com

Competing interests: None
}

\section{INTRODUCTION}

section rate for many years. ${ }^{6-7}$ Many interventions have been proposed on this regard, especially focusing on reduction of planned Caesarean sections. Previous Caesarean section is a common indication for planned caesarean section. ${ }^{8}$ Therefore, making vaginal birth after caesarean section (VBAC) a safe and successful option has been proposed as an effective way of reducing the planned Caesarean section rate. It has been introduced in to clinical practice in many obstetric units worldwide.

Women who undergo a VBAC have a higher risk of requiring an emergency caesarean section than a woman who has not had previous caesarean section. Such an emergency procedure may confer a higher risk of complications, than a planned Caesarean section. As the success rate of VBAC show wide variation between different patient groups and clinical settings, it is important to audit the performance of individual settings to assess the success rate and factors associated with failure. Such information would be useful for patient counseling prior to VBAC as well as to identify any shortcomings in our service delivery. The woman herself in many settings makes the choice of VBAC, and therefore, it is very important that the clinicians are able to provide with accurate and focused information that will help the woman the make a decision. Such information should be relevant to the clinical setting that the woman is managed.

The identification of factors associated with failure would also be helpful in identifying suitable patients for VBAC.

Audit criteria with accepted standards and secondary objectives

1. The success rate of VBAC in women who have had a single previous section to be $72 \%$. 
- This standard was arrived according to RCOG green top guideline that describes the success rate to be $72-76 \%{ }^{7}$

2. The proportion of neonates with a $5 \mathrm{~min}$ APGAR score to be less than $5 \%$.

- Since there are no clinical recommendations on this, the figure of $5 \%$ was arrived at by observation of incidence among low risk vaginal deliveries.

Secondary objectives

- To identify the factors that are associated with failure of VBAC among women who undergo a VBAC.

\section{METHODS}

Study design: A prospective audit was performed from July 2009 to April 2011 at ward 21 and 22 of Colombo South Teaching Hospital, Kalubowila and ward five and two of De Soysa hospital for women, Colombo 08. Women who underwent a VBAC at study centers during the study periods made the potential study population. The inclusion criteria used for subject recruitment included a singleton pregnancy with cephalic presentation between 37 weeks to 41weeks of gestation and planned for a VBAC. The exclusion criteria used included a history of more than one caesarean section, a classical caesarean section, and complications at previous Caesarean delivery contraindicating VBAC, previous gynaecological surgery with uterine incisions or fetuses with congenital anomalies or severe growth restriction.

The existing practice: In these units the policy is to offer VBAC to all women considered suitable for vaginal birth after Caesarean (VBAC). A detailed history with an emphasis on the previous Caesarean would be elicited to identify any contraindications to VBAC. Those who are deemed suitable for VBAC would be offered detailed counseling that includes the advantages and disadvantages of both approaches and the patient will make an informed choice with regard to VBAC. Management of those who opt for VABC included waiting for spontaneous onset of labour as induction with prostaglandin and augmentation with Oxytocin were not undertaken in the units. Artificial rupture of membranes was done for augmentation of labour if required. If the woman had not gone in to labour by the end of 41 weeks of gestation, a cervical assessment was done. If the modified Bishop's score was 6 or more, artificial rupture of membrane was offered. If the cervix was not favorable at 41 weeks, the women were offered a planned Caesarean section and hence not included in the study. The patient management protocols of the units were not modified for the purpose of the study.

Study interventions: All women who were included in the audit were informed of the study and written consent was obtained. A clinical interview was conducted at the beginning of VBAC and socio demographic data were recorded. The booking height and weight were recorded from the antenatal record. The cervical dilatation and position of the fetal head were assessed at commencement of labour. Management of labour was as per unit protocol and continuous electronic fetal monitoring was done using cardiotocography throughout labour in all patients undergoing VBAC. No specific time limit was set for a trial of labor and any decision on emergency caesarean delivery was made at the discretion of the clinician on duty. The

\section{Figure1. The sucess rate of VBAC among women who underwent VBAC}

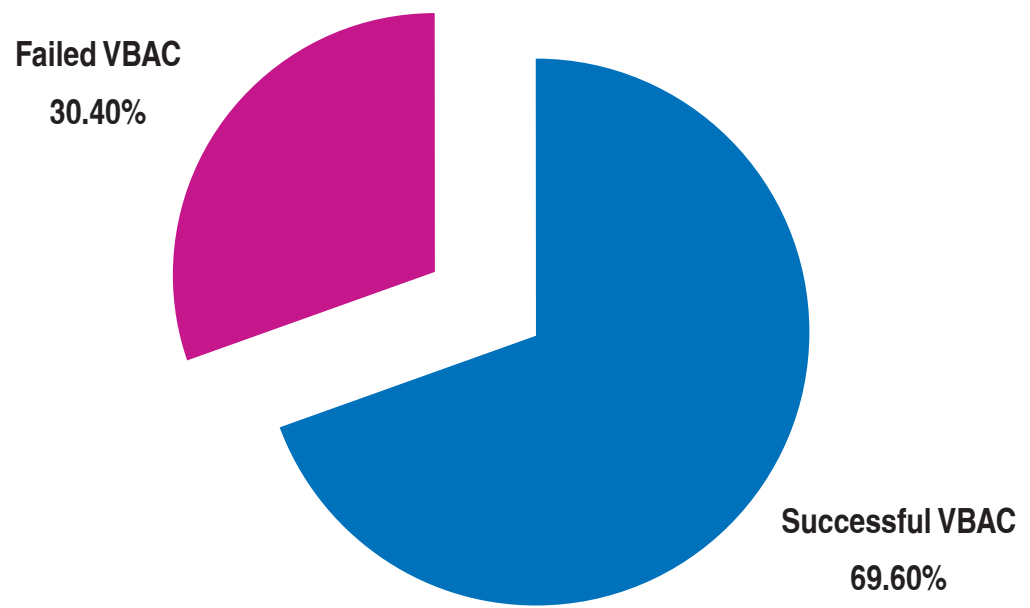

June 2015 Sri Lanka Journal of Obstetrics and Gynaecology 
Among women who underwent a VBAC, 112 had a vaginal delivery. The rate of successful caesarean section was $69.6 \%(95 \% \mathrm{CI}=62.5-76.7)$. This was $84.6 \%$ for women who had one or more vaginal deliveries prior to the index VBAC, while it was $64.8 \%$ for those who did not have a history of a vaginal delivery.

A low APGAR score $(<7)$ at 5 minutes was observed in two subjects $(1.2 \%)$ of the total study population who attempted a VBAC. No other serious perinatal morbidity or mortality was detected in this group.

The failure rate of VBAC was $31.4 \%$ in this study population. The factors that

Table 2. The factors associated with failure of VBAC among the study population.

\begin{tabular}{|c|c|c|c|}
\hline & $\begin{array}{l}\text { Failed VBAC } \\
n=49\end{array}$ & $\begin{array}{l}\text { Successful VBAC } \\
n=112\end{array}$ & $\begin{array}{l}\text { Odds ratio }(95 \% \\
\mathrm{Cl})\end{array}$ \\
\hline $\begin{array}{l}\text { Previous vaginal deliveries; No } \\
\text { None } \\
\text { One or more }\end{array}$ & $\begin{array}{l}43(87.7 \%) \\
6(12.2 \%)\end{array}$ & $\begin{array}{l}79(70.5 \%) \\
33(29.4 \%) \\
\end{array}$ & $2.99(1.17-7.64)$ \\
\hline $\begin{array}{l}\text { Indication for previous section } \\
\text { Poor progress } \\
\text { Other indications }\end{array}$ & $\begin{array}{l}19(38.7 \%) \\
30(61.2 \%)\end{array}$ & $\begin{array}{l}24(21.4 \%) \\
88(78.5 \%)\end{array}$ & $2.32(1.13-4.79)$ \\
\hline $\begin{array}{l}\text { Booking BMI } \\
\mathrm{BMl}>30 \\
\mathrm{BMl}<30\end{array}$ & $\begin{array}{l}9(18.3 \%) \\
40(81.6 \%)\end{array}$ & $\begin{array}{l}14(12.5 \%) \\
98(87.5 \%)\end{array}$ & $1.57(0.64-3.86)$ \\
\hline $\begin{array}{l}\text { Onset of labour } \\
\text { Augmented by ARM } \\
\text { Spontaneous }\end{array}$ & $\begin{array}{l}31(63.2) \\
18(36.7 \%) \\
\end{array}$ & $\begin{array}{l}59(52.6 \%) \\
53(47.3 \%) \\
\end{array}$ & $1.55(0.78-3.07)$ \\
\hline $\begin{array}{l}\text { Cervical dilatation } \\
\text { Cervix }<2 \mathrm{~cm} \\
\text { Cervix }>2 \mathrm{~cm}\end{array}$ & $\begin{array}{l}17(34.6 \%) \\
32(65.3 \%) \\
\end{array}$ & $\begin{array}{l}12(10.7 \%) \\
100(89.2 \%)\end{array}$ & $4.43(1.94-10.13)$ \\
\hline $\begin{array}{l}\text { Positions in early labour } \\
\text { Non OA } \\
\text { OA }\end{array}$ & $\begin{array}{l}28(57.1 \%) \\
21(42.8 \%)\end{array}$ & $\begin{array}{l}11(9.8 \%) \\
101(90.1 \%)\end{array}$ & $\begin{array}{lll}12.24 & (5.32 \quad- \\
28.15) & \end{array}$ \\
\hline $\begin{array}{l}\text { Birth weight } \\
\text { BW }>3 \mathrm{~kg} \\
\text { BW }<3 \mathrm{~kg}\end{array}$ & $\begin{array}{l}30(61.2 \%) \\
19(38.7 \%) \\
\end{array}$ & $\begin{array}{l}48(42.8 \%) \\
64(57.1 \%) \\
\end{array}$ & $2.11(1.06-4.16)$ \\
\hline $\begin{array}{l}\text { Inter-delivery interval } \\
\text { Interval }<2 \text { years } \\
\text { Interval }>2 \text { years }\end{array}$ & $\begin{array}{l}6(12.2 \%) \\
43(87.7 \%)\end{array}$ & $\begin{array}{l}13(11.6 \%) \\
99(88.3 \%)\end{array}$ & $1.06(0.39-2.91)$ \\
\hline
\end{tabular}

Statistically significant associations are shown in bold. were associated with failure of VBAC included not having had any previous vaginal deliveries, poor progress being the indication for previous Caesarean, a cervical dilatation of less than $2 \mathrm{~cm}$ at admission to labour ward, malpositions in early labour and a birth weight of more than $3 \mathrm{~kg}$. Among these factors, malpositions in early labour showed the strongest association with failure of VBAC followed by unfavourable cervix at the onset of labour and not have had a vaginal delivery in the past. The associations of these factors are shown in table 2.

\section{DISCUSSION}

For a woman who has undergone a Caesarean section, the two options for delivery are VBAC or a planned repeat Caesarean section. Either of these methods will have their own advantages and disadvantages. An attempt at a vaginal birth will have a higher risk of uterine rupture (approx. 1:200), need for blood transfusions (additional 1\% risk), infectious morbidity, increased risk for hysterectomy, fetal acidosis, hypoxic encephalopathy and perinatal death when compared with a planned repeat Caesarean section., ${ }^{79-11}$ However, the benefits of VBAC include reduction of neonatal respiratory morbidity $(2-3 \%$ vs. $3-4 \%)$ and reducing the risk of serious complications in future pregnancies that are related to abnormal placentation we well as repeated Caesarean sections. It also results in a faster recovery and early mobilization. While this reduce the risk of thrombo-embolic events in the mother, it allows the woman to get back to her day to day work thus allowing the woman to be able to care for herself and the baby. The lesser burden on the health system should also be a consideration since Caesarean section would require more resources including longer hospital bed occupancy.

This study was able to demonstrate that the proportion of women who take up VBAC after one previous Caesarean section in a Sri Lankan setting is less than $40 \%$. It was not clear in this study the proportion that were not offered and the proportion that declined VBAC. However, the overall rate of accepting VBAC in this audit is very low compared to units in other parts of the world that describe rates above $50 \%$. ${ }^{12,13}$ Many factors may contribute to a lower rate of recommending VBAC by clinicians and acceptance by women in our clinical setting. These would include the unavailability of dedicated obstetric operating theatres to attend to acute fetal distress due to impending scar rupture, limitations in use of continuous electronic monitoring during VBAC and nonpractice of fetal blood sampling to confirm fetal distress with equivocal CTG tracings. 
Success rate of VBAC at study units $(69 \%)$ fell just short of the standard that was set at $72 \%$ based on the rates described in RCOG Green top guideline. ${ }^{7}$ This was comparable with data from other centers, which have reported rates between $56 \%-80 \%{ }^{14-}$ 17 The success rate at VBAC among women who have had a previous vaginal delivery was increased up to $84 \%$ and was slightly lower than data from previous studies that describes success rates between $87-90 \% .^{18-21}$

Only $1.2 \%$ of the neonates born after VBAC had a low APGAR score of $<7$ at 5 minutes from birth. They belonged to the successful VBAC group while none were in the failed VBAC group. This rate was better than our set standard of less than 2\%. APGAR scare at 5 minutes is not the best method of assessing neonatal outcome of VBAC but was used due to much less occurrence of other complications of respiratory distress and ischemic encephalopathy.

This study was able to identify factors that are associated with failure at VBAC in a Sri Lankan population. The factors that have been identified to be associated with outcome of VBAC include an advanced maternal age, a history of vaginal deliveries before or after the LSCS, a higher BMI of $>30$, an inter-delivery interval of less than 2 years, a birth weight less than $3000 \mathrm{~g}$, a cervical dilatation more than $2 \mathrm{~cm}$ at the onset of labour, and indication for the previous LSCS being poor progress in labour. ${ }^{14,22-26}$ Of these factors, those that were observed to be associated with failure in our study included non-occipital anterior position at onset of labour (12 times higher risk), A cervical dilatation of $<2 \mathrm{~cm}$ at onset of labour (4.5 times higher risk), no vaginal births previously (3 times higher risk), poor progress of labour being the indication for previous Caesarean (2.3 times higher risk), and a birth weight of more than $3 \mathrm{~kg}$ (2 times higher risk). Such information is useful in-patient counseling prior to VBAC so that clinicians would be able to discuss the chance of success at a more individualized basis.
Advanced maternal age, an inter delivery interval less than two years and a higher maternal booking BMI failed to demonstrate such associations in our study. ${ }^{27}$ However, since this was not a properly powered study to detect or exclude such associations, it is difficult to comment such absence is an accurate observation. Other studies have studied induction and need for augmentation of labour with oxytocin as factors associated with failure of VBAC. . $3,28,29$ However, we could not assess such association as induction of labour with prostaglandin or augmentation with oxytocin are not included in the VBAC management protocols of these units.

\section{LIMITATIONS}

This study had some limitations in its study design. Since we did not look in detail the number of suitable women who were offered VBAC but declined, we were not able to draw firm conclusions on the acceptance rate of VBAC in a local population. The selection of women for VBAC was not according to a strict protocol but by clinical practice of the units, thus the results of this study may have limitations in generalization in other units.

\section{RECOMMENDATIONS AND FUTURE DIRECTIVES}

In conclusion, we wish to make the following recommendations. The total uptake rate of VBAC among women with a single previous Caesarean section seems to be low among our study centers. More in depth studies are required to identify the reasons for such lower rates so that corrective measures can be proposed. The success rate among women who accept VBAC seems to be comparable to set standards and this data should be used effectively in patient counseling and re-audits should be undertaken regularly. Similar audits are recommended in other local centers to make comparisons for similarclinical settings in Sri Lanka.

\section{REFERENCES}

1. Goonewardene M, Kumara DMA, Jathun Arachchi DR, Vithanage R, Wijeweera $R$. The rising trend in caesarean section rates: should we and can we reduce it? Sri Lanka Journal of Obstetrics and Gynaecology 2012; 34: 11-8

2. Black C, Kaye JA, Jick H. Cesarean delivery in the United Kingdom: time trends in the general practice research database. Obstetrics and Gynecology 2005;106:151-5.

3. Liu S, Rusen ID, Joseph KS, Liston R, Kramer MS, Wen SW, et al. Recent trends in caesarean delivery rates and indications for caesarean delivery in Canada. Journal of Obstetetrics and Gynaecology Canada 2004;26: 735-42.

4. Medical statistics unit. Annual Health Bulletin of Sri Lanka 1999. Ministry of Health, Colombo, Sri Lanka.

5. Medical statistics unit. Annual Health Bulletin of Sri Lanka 2006. Ministry of Health, Colombo, Sri Lanka.

6. World Health Organization. Appropriate technology for birth. The Lancet 1985; 2(8452): 436-7

7. Royal College of Obstetricians and Gynaecologists. Birth after previous Caesarean delivery, Green-top guideline No 45, 2007. RCOG press, London, UK.

8. Wang CP, Tan WC, Kanagalingam D, Tan HK. Why we do Caesars: a comparison of the trends in caesarean section delivery over a decade. ANNALS academy of medicine Singapore 2013; 42: 408-12.

9. Hibbard JU, Ismail MA, Wang Y, Te C, Karrison $\mathrm{T}$, Ismail MA. Failed vaginal birth after a Cesarean section: how risky is it? I. Maternal morbidity. American Journal of Obstetrics and Gynecology 2001; 184(7): 1365-71

10. Landon MB, Hauth JC, Leveno KJ, Spong CY, Leindecker S, et al. Maternal and Perinatal Outcomes Associated with a Trial of Labor after Prior Cesarean Delivery. New England Journal of Medicine 2004; 351: 2581-9.

11. Chauhan SP, Martin JN Jr, Henrichs CE, Morrison JC, Magann EF. Maternal and perinatal complications with uterine rupture in 142,075 patients who attempted vaginal birth after cesarean delivery: $A$ review of the literature. American Journal of Obstetetrics and Gynecology. 2003; 189(2): 408-17 
12. Lau TK, Wong SH, Li CY. A study of patients' acceptance towards vaginal birth after caesarean section. Australian and New Zealand Journal of Obstetrics and Gynaecology 1996; 36(2):155-8.

13. Singh T, Justin CW, Haloob RK. An audit on trends of vaginal delivery after one previous caesarean section. Journal of Obstetrics \& Gynaecology 2004; 24(2): 135-8

14. Landon MB, Leindecker S, Spong CY, Hauth JC, Bloom S, Varner MW, et al. MFMU Cesarean Registry: factors affecting the success of trial of labor after previous cesarean delivery. American Journal of Obstetrics and Gynecology 2005; 193:1016-23

15. Stone C, Halliday J, Lumley J, Brennecke S. Vaginal birth after caesarean (VBAC): a population study. Paediatric Perinatal Epidemiology 2000; 14: 340-8.

16. Pathiraja R, Jayawardane MAMM, Gamage DOM, Liyanage Gl, Wijayarathne AKJM. Outcome of vaginal birth after caesarean section in a tertiary care unit. Sri Lanka Journal of Obstetrics and Gynaecologists 2011; 33; 58-9.

17. Guise JM, Berlin M, McDonagh $M$, Osterweil $P$, Chan B, Helfand $M$. Safety of vaginal birth after cesarean: a systematic review. Obstetrics and Gynecology 2004; 103(3): 420-9
18. Smith GC, White IR, Pell JP, Dobbie R. Predicting cesarean section and uterine rupture among women attempting vaginal birth after prior Cesarean section. PLOS Medicine 2005; 2: 871-8.

19. Gyamfi C, Juhasz G, Gyamfi P, Stone JL. Increased success of trial of labor after previous vaginal birth after Cesarean. Obstetrics \& Gynecology 2004; 104: 715-9

20. Hibbard JU, Gilbert S, Landon MB Hauth JC, Leveno KJ, Spong CY, et al. Trial of labor or repeat cesarean delivery in women with morbid obesity and previous Cesarean delivery. Obstetrics \& Gynecology 2006; 108: 125-33.

21. Goodall PT, Ahn JT, Chapa JB, Hibbard JU. Obesity as a risk factor for failed trial of labor in patients with previous Cesarean delivery. American Journal of Obstetrics and Gynecology 2005; 192: 1423-6.

22. Brill $Y$, Windrim R. Vaginal birth after Caesarean section: review of antenatal predictors of success. Journal of Obstetrics and Gynaecology Canada 2003; 25(4): 275-86

23. Tripathi JB, Doshi HU, Kotdawala PJ. Vaginal birth after one caesarean section: analysis of indicators of success. Journal of Indian Medical Association 2006; 104(3): 113-5
24. Shimonovitz S, Botosneano A, HochnerCelnikier D. Successful first vaginal birth after cesarean section: a predictor of reduced risk for uterine rupture in subsequent deliveries. Israel Medical Association Journal 2000; 2(7): 526-8

25. Bujold $E$, Hammoud AO, Hendler I, Berman S, Blackwell SC, Duperron L, et al. Trial of labor in patients with a previous cesarean section: does maternal age influence the outcome? American Journal of Obstetrics \& Gynecology 2004; 190: 1113-8

26. Shipp TD, Zelop C, Repke JT, Cohen $A$, Caughey $A B$, Leiberman $E$. The association of maternal age and symptomatic uterine rupture during a trial of labor after prior cesarean delivery. Obstetrics \& Gynecology 2002; 99: 585-8

27. Bujold E, Hammoud A, Schild C, Krapp $M$, Baumann $P$. The role of maternal body mass index in outcomes of vaginal births after cesarean. American Journal of Obstetrics and Gynecology 2005; 193(4): 1517-21

28. Durnwald C, Mercer B. Vaginal birth after Cesarean delivery: predicting success, risks of failure. Journal of Maternal-Fetal and Neonatal medicine 2004; 15(6): 38893

29. Tan PC, Subramaniam RN, Omar SZ. Predictors for caesarean delivery and neonatal admission after trial of labour in women with one previous lower segment caesarean scar. Singapore Medical Journal 2008; 49(3): 188 